\title{
FORMULASI STRATEGI BERSAING DI KAFE DAN ANGKRINGAN NU LAHARJO MOJOKERTO
}

\section{Zenita Afifah Fitriyani}

Fakultas Ekonomi, Universitas Mayjend Sungkono Mojokerto zenitaafifah@gmail.com

\section{Mokhammad Ridha}

Fakultas Ekonomi, Universitas Mayjend Sungkono Mojokerto mokhafiesta@gmail.com

\section{Sugeng Eko Yuli Waluyo}

Fakultas Ekonomi, Universitas Mayjend Sungkono Mojokerto sugeng.windurejo@gmail.com

\begin{abstract}
The purpose of this study is to identify SWOT analysis and formulate business strategies using IFE and EFE Matrix, Grand Strategy Matrix, and strategy formulation with SWOT Matrix at Café and Angkringan Nu Laharjo Mojokerto. The benefit of this research is the identification of SWOT analysis and strategy formulation that can be used as a measure in future business planning. The research used is qualitative research with data collection method using purposive sampling. while the data analysis technique uses descriptive analysis, which describes the data collected using SWOT analysis, IFE and EFE Matrix, Grand Strategy Matrix, and strategy formulation with SWOT Matrix. The results showed that the SWOT analysis was identified, the IFE and EFE Matrix had a positive total score, and the Grand Strategy Matrix showed that Nu Laharjo Café and Angkringan were in Quadrant I, which had a strategic and good position. In addition, the strategy formulation is also identified in the SWOT matrix, so that Kafe and Angkringan Nu Laharjo can use this strategy to survive in the face of competitors.
\end{abstract}

Keywords: strategy formulation, swot analysis, ife and efe matrix, grand strategy matrix.

Corresponding author:

Email Address : zenitaafifah@gmail.com(Mojokerto, Jawa Timur)

Received 6 Mei 2021, Accepted 15 Agustus 2021, Published 22Agustus 2021

\section{PENDAHULUAN}

Pandemi Covid-19 memberikan dampak yang besar di berbagai sektor bisnis di Indonesia. Salah satunya adalah bisnis kafe yang aktivitas usahanya berubah drastis. Kesemua itu dikarenakan kafe merupakan tempat berkumpul, bercengkrama, dan bekerja, sehingga kafe menjadi sepi karena terdapat aturan social distancing dari pemerintah. Selain itu, kafe harus membatasi jam operasional karena ada pembatasan wilayah atau pembatasan fisik. Akibatnya, omset yang didapatkan mengalami penurunan. Seperti yang dikemukakan oleh Tjahyono Haryono (Ketua Asosiasi Pengusaha Kafe dan Restoran
Indonesia) bahwa semua pengusaha kuliner saat ini sedang kesulitan.

Semua cara sudah dilakukan untuk tetap bisa bertahan, seperti memanfaatkan online marketing sampai membuat menu baru, tetapi tidak bisa meningkatkan penjualan, sehingga revenue menjadi turun. Menurut Arifin dkk (2021) bahwa dampak terbesar pandemi Covid-19 bagi UMKM, yaitu: 75\% pemilik usaha mengalami penurunan pendapatan secara signifikan; $51 \%$ meramalkan jika usaha mereka hanya bertahan dalam waktu 3 bulan; $75 \%$ tidak mengerti kebijakan dalam 
keadaan krisis; $13 \%$ pemilik usaha memiliki rencana dalam menyelamatkan usahanya.

Fenomena tersebut juga terjadi pada Kafe dan Angkringan "Nu Laharjo" yang berada di Kota Mojokerto, di mana pada masa pandemi Covid-19. Kafe tetap buka dengan perubahan jam operasional, yaitu dari pukul 10.00 - 24.00 WIB menjadi pukul 12.00 - 20.00 WIB. Saat masa pasca pandemi, jam operasional kembali normal dan tetap memperhatikan prosedur kesehatan. Pada area diluar kafe menyediakan tempat cuci tangan, penyediaan handsanitizer di dekat kasir, serta memberi batas jarak 1,5 meter setiap meja. Adanya menu baru menjadi kekuatan baru bagi Kafe dan Angkringan "Nu Laharjo", seperti: "ayam geprek, nasi bertelor dan milkshake" menjadi keunggulan dan alternatif penjualan.

Selain itu, pihak kafe melakukan promosi, melalui media sosial dan memberikan diskon untuk pembelian "ayam geprek dan milkshake" secara bersamaan untuk menarik minat pelanggan. Namun, tetap saja omset yang didapatkan belum meningkat secara signifikan. Persaingan dengan kafe - kafe lain yang sejenis juga semakin tinggi, karena setiap kafe berusaha untuk menonjolkan keunggulannya masing - masing. Terlebih lagi kafe sejenis yang berada di sekitar Kafe dan Angkringan "Nu Laharjo" yang juga berlomba - lomba untuk mengikat hati konsumen.

Kafe "NCO" dalam merebut hati konsumen pihak kafe melakukan strategi dekorasi internal kafe dengan membuat secret garden, sehingga yang diingat konsumen saat datang ke kafe adalah konsumen akan merasa menikmati makanan dan minuman di kebun ketika berada disitu. Terdapat Kafe "Pasta Kangen", di mana kafe tersebut menjual aneka macam makanan western dan lokal, dengan menawarkan "spageti" sebagai menu utama. Kafe Pasta Kangen juga menyuguhkan live music saat weekend, sehingga konsumen lebih ramai datang saat weekend. Sementara, Kafe "Budaya Kopi", di mana kafe tersebut memiliki keunggulan pada racikan kopi, karena menyediakan berbagai macam kopi baik hot maupun cold, seperti: kopi javanica, kopi hijau tulungagung, kopi tubruk, kopi Vietnam, espresso, macchiato, latte, cappuccino dan sebagainya, sehingga menjadi tujuan datangnya pecinta kopi.

Kafe "NCO", Kafe "Pasta Kangen" dan Kafe "Budaya Kopi" menjadi ancaman terbesar, karena lokasinya terletak di dekat Kafe dan Angkringan "Nu Laharjo". Oleh Karena itu, diperlukan formulasi strategi manajemen dalam menganalisis kondisi internal dan eksternal di Kafe dan Angkringan "Nu Laharjo". Manajemen strategis dapat mendukung keberjalanan sebuah bisnis, karena dapat merumuskan, melaksanakan, dan mengevaluasi keputusan bisnis dalam mencapai tujuan (Tuncay \& Musa, 2015). Salah satu fase dalam proses manajemen strategi adalah analisis internal dan eksternal.

Strategi yang dapat digunakan dalam menganalisis kondisi internal dan eksternal organisasi adalah analisis SWOT, di mana organisasi mengidentifikasi kondisi eksternal dari ancaman kritis dan peluang dalam lingkungan kompetitif. Pada kondisi internal, analisis berfokus pada kekuatan dan kelemahan perusahaan, ehingga analisis SWOT dapat dikatakan sebagai alat perencanaan strategis yang digunakan untuk mengevaluasi kekuatan, kelemahan, peluang, dan ancaman organisasi untuk memberikan informasi dalam menyesuaikan sumber daya dan kemampuan organisasi dengan lingkungan persaingan yang dioperasikannya (Emet \& Merba, 2017). Matriks SWOT dapat digunakan perusahaan perusahaan dalam memformulasikan strategi yang efektif, karna sudah terbukti secara teori dan praktik organisasi (Sitorus dkk, 2019).

Hasil penelitian terdahulu yang dilakukan oleh Sanjaya dkk (2020) menyebutkan menggunakan analisis IFE dan EFE serta matriks grand strategy pada 12 usaha kuliner di Provinsi Lampung. Selanjutnyaa, didapatkan hasil industry kuliner di Lampung berada pada posisi Kuadran I dengan pertumbuhan pasar yang tinggi dan posisi kompetitif yang kuat. Penelitian Kamaluddin (2020) juga menggunakan matriks IFAS dan EFAS untuk mengetahui posisi PT. Menara Angkasa Semesta Cabang Sentani. Diketahui hasil penelitian bahwa posisi perusahaan berada pada diagram IE di Kuadran V, yaitu fase pertumbuhan dan stabilitas.

Penelitian Purwohandoyo dkk (2020) juga menunjukkan dengan menggunakan metode SWOT kuantitatif menghasilkan 12 desa wisata berada di Kuadran I, satu desa wisata berada di kuadran II, dan dua desa wisata berada di kuadran IV. Mengacu pada fenomena tersebut, rumusan masalah adalah bagaimana mengidentifikasi faktor kekuatan (strengths), 
kelemahan (weaknesses), peluang (opportunities), dan ancaman (threats), serta bagaimana memformulasikan strategi bisnis dengan menggunakan matrik IFE dan EFE serta matrik grand strategy pada Kafe dan Angkringan "Nu Laharjo Mojokerto" dalam mempertahankan persaingan bisnisnya, sehingga tujuan dari penelitian ini adalah untuk mengidentifikasi faktor kekuatan (strengths), kelemahan (weaknesses), peluang (opportunities), dan ancaman (threats) dan memformulasikan strategi bisnis menggunakan matrik IFE dan EFE, serta matrik grand strategy pada Kafe dan Angkringan "Nu Laharjo". Manfaat penelitian ini adalah identifikasi SWOT dan formulasi strategi dapat dijadikan ukuran dalam perencanaan bisnis yang akan datang.

\section{METODOLOGI PENELITIAN \\ Objek Penelitian}

Penelitian dilakukan di Kafe dan Angkringan $\mathrm{Nu}$ Laharjo Mojokerto berlokasi di jalan Lotus No. 36 Mojokerto selama bulan Februari Maret 2021.

\section{Jenis Penelitian}

Jenis penelitian yang digunakan yaitu penelitian kualitatif (eksploratif) dimana penelitian dilakukan dengan menggali penyebab terjadinya masalah sebelum peneliti mengetahuinya. Tujuan dari metode tersebut yaitu untuk dapat menggambarkan dan menjelaskan objek secara mendalam (Arifin et al., 2021). Metode pengambilan sampel yaitu menggunakan Purposive Sampling, dimana sampel dipilih sengaja berdasarkan kriteria yang ditentukan agar representatif (Pratama \& Rivai, 2021), sehingga data primer diperoleh dari data penyebaran kuesioner dari pelanggan, dan data wawancara kepada informan terpilih yaitu pemilik usaha dan karyawan Kafe dan Angkringan Nu Laharjo Mojokerto. Sedangkan data sekunder diperoleh dari data penjualan, data harga dan jenis produk yang dijual, data fasilitas kafe, buku, proceeding, jurnal nasional dan internasional yang menunjang penelitian.

\section{Teknik Analisis Data}

Teknik analisis data menggunakan analisis deskriptif yaitu menganalisa dengan cara mendeskripsikan dan menggambarkan data yang dikumpulkan dengan menggunakan Analisis SWOT, Matriks IFE dan EFE, Matrik
Grand Strategy, serta formulasi strategi Matrik SWOT.

Analisis SWOT adalah matriks yang digunakan untuk menganalisis kekuatan (strengths), kelemahan (weaknesses), peluang (Opportunities), dan ancaman (threats) yang dilakukan untuk memperoleh strategi umum untuk dapat memanfaatkan kekuatan dan peluang serta meminimalkan kelemahan dan ancaman (Evelyn, 2018). Analisis SWOT juga digunakan sebagai pertimbangan atas potensi dan kemungkinan yang ada, sehingga analisis tersebut bisa menjadi perencanaan yang efektif dan efisien (Rawung \& Salindeho, 2020).

Matriks IFE (Internal Factor Evaluation) dan EFE (External Factor Evaluation) digunakan untuk mengelompokkan faktor internal dan eksternal berdasarkan tingkat kepentingannya yang terdiri dari kolom, bobot, rating dan kolom nilai (Astuti \& Ratnawati, 2020). IFE merupakan analisis dari berbagai faktor internal, sedangkan EFE adalah analisis dari berbagai faktor eksternal yang mempengaruhi keberlangsungan perusahaan (Syamruddin, 2020).

Matriks Grand Strategy merupakan matriks yang dapat disusun berdasarkan urutan daya tarik pada setiap kuadran matriks. Matriks ini membagi grand strategy dalam 10 bagian, antara lain turn around, likuidasi, integrasi vertikal, diversifikasi, konglomerasi, konsentrasi, pengembangan produk dan pasar, inovasi, integrasi horizontal, diversifikasi konsentrat, dan joint venture (Sanjaya et al., 2020).

Matrik SWOT digunakan sebagai formulasi strategi dalam pengembangan usaha, dimana memiliki empat tipe strategi, yaitu strategi SO yang digunakan dengan memanfaatkan kekuatan untuk merebut peluang, strategi WO digunakan dalam meminimalkan kelemahan untuk memanfaatkan peluang, strategi ST yaitu dengan memanfaatkan kekuatan untuk menghadapi ancaman, serta strategi WT yang digunakan untuk meminimalkan kelemahan untuk menghindari ancaman (Sari et al., 2021).

Kegiatan penelitian yang dilakukan yaitu dengan melakukan penelitian pendahuluan untuk mendapatkan gambaran dan latar belakang permasalahan, selanjutnya menyusun draf kuesioner dan wawancara serta melakukan penyebaran, kemudian data hasil penyebaran kuesioner dan wawancara diolah untuk 
membuat identifikasi SWOT, matriks IFE dan EFE, matriks grand strategy serta membuat formulasi strategi dalam bersaing. Adapun kegiatan penelitian tersebut dapat dilihat pada gambar diagram alir dibawah ini,

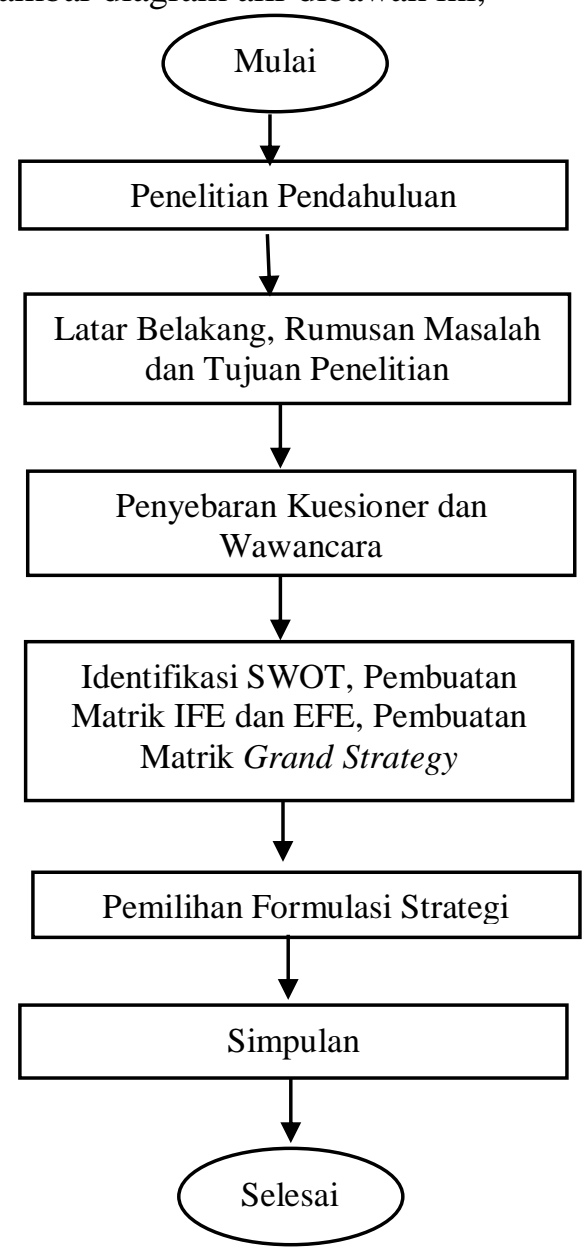

Gambar 1. Diagram Alir Penelitian

\section{HASIL}

Hasil penelitian yang dilakukan, maka didapatkan hasil penelitian berupa data analisis SWOT, matriks IFE dan EFE, dan matriks "Grand Strategy". Selanjutnya, data tersebut dianalisa dan dibahas untuk mendapatkan formulasi strategi bersaing pada Kafe dan Angkringan "Nu Laharjo" Kota Mojokerto.

\section{Analisis SWOT}

Analisis SWOT dilakukan untuk merumuskan strategi dengan mengkombinasikan kekuatan, kelemahan, peluang, dan ancaman perusahaan (Qanita, 2020). Adapun kerangka analisis SWOT pada Kafe dan Angkringan "Nu Laharjo" Kota Mojokerto dapat dilihat pada Tabel 1 .
Tabel 1. Analisis SWOT

\begin{tabular}{|c|c|c|c|}
\hline \multicolumn{4}{|c|}{ Analisis SWOT } \\
\hline No & Strengths & No & Weaknesses \\
\hline 1 & $\begin{array}{l}\text { Harga produk } \\
\text { terjangkau }\end{array}$ & 1 & $\begin{array}{l}\text { Sarana promosi } \\
\text { belum maksimal }\end{array}$ \\
\hline 2 & $\begin{array}{l}\text { Tempat strategis, } \\
\text { luas, dan nyaman }\end{array}$ & 2 & $\begin{array}{l}\text { Keberhasilan } \\
\text { media sosial } \\
\text { terbatas (jumlah }\end{array}$ \\
\hline 3 & $\begin{array}{l}\text { Menyediakan } \\
\text { fasilitas wifi, toilet, } \\
\text { dan musholla }\end{array}$ & & $\begin{array}{l}\text { follower belum } \\
\text { menjangkau } \\
\text { secara luas) }\end{array}$ \\
\hline 4 & $\begin{array}{l}\text { Menyediakan menu } \\
\text { yang bervariasi }\end{array}$ & 3 & $\begin{array}{l}\text { Brand awareness } \\
\text { masih rendah }\end{array}$ \\
\hline 5 & $\begin{array}{l}\text { Menyediakan menu } \\
\text { tambahan (ayam } \\
\text { geprek, nasi } \\
\text { bertelor dan } \\
\text { milkshake) }\end{array}$ & 4 & $\begin{array}{l}\text { Kompetitor yang } \\
\text { lebih kuat }\end{array}$ \\
\hline 6 & $\begin{array}{l}\text { Loyalitas konsumen } \\
\text { tinggi }\end{array}$ & & \\
\hline No & Opportunities & No & Threats \\
\hline 1 & $\begin{array}{l}\text { Mengembangkan } \\
\text { inovasi produk baru }\end{array}$ & 1 & $\begin{array}{l}\text { Adanya } \\
\text { pembatasan } \\
\text { sosial }\end{array}$ \\
\hline 2 & $\begin{array}{l}\text { Menjaga hubungan } \\
\text { baik dengan } \\
\text { konsumen }\end{array}$ & 2 & $\begin{array}{l}\text { Persaingan usaha } \\
\text { sejenis }\end{array}$ \\
\hline 3 & $\begin{array}{l}\text { Menarik konsumen } \\
\text { dengan harga } \\
\text { promo }\end{array}$ & 3 & $\begin{array}{l}\text { Konsumen } \\
\text { beralih ke Kafe } \\
\text { lain }\end{array}$ \\
\hline 4 & $\begin{array}{l}\text { Melayani penjualan } \\
\text { melalui aplikasi } \\
\text { online }\end{array}$ & 4 & $\begin{array}{l}\text { Kenaikan harga } \\
\text { bahan baku }\end{array}$ \\
\hline
\end{tabular}

Sumber : Data Diolah (2021)

Tabel 1. mengidentifikasi beberapa faktor internal usaha, meliputi: stengths dan weaknesses, serta faktor eksternal yang meliputi opportunities dan threats dimana pada dasarnya analisis SWOT bertujuan dalam menggali aspek SWOT, sehingga Kafe dan Angkringan "Nu Laharjo" dapat memaksimalkan strengths dan opportunities, serta meminimalkan weaknesses dan threats. Dadang (2020) mengemukakan bahwa dalam memaksimalkan kekuatan dan peluang yang bersamaan dengan meminimalkan kelemahan dan ancaman, maka perlu dirumuskan strategi perusahaan dengan mengidentifikasi berbagai faktor secara sistematis yang kemudian di analisa dengan matrik IFE dan EFE. 
Matrik IFE dan EFE

Matriks IFE (Internal Factor Evaluation) dan EFE (External Factor Evaluation) digunakan untuk mengidentifikasi faktor internal dan eksternal dalam bentuk perhitungan bobot, rating, dan skor pada Kafe dan Angkringan "Nu Laharjo" Kota Mojokerto. Hal itu dapat dilihat pada Tabel 2. dan Tabel 3.

Tabel 2. Matrik IFE

\begin{tabular}{|c|c|c|c|c|}
\hline \multirow{2}{*}{ No } & Faktor Internal & \multirow{2}{*}{ Bobot } & \multirow{2}{*}{ Rating } & \multirow{2}{*}{ Nilai } \\
\hline & Strength & & & \\
\hline 1 & $\begin{array}{l}\text { Harga produk } \\
\text { terjangkau }\end{array}$ & 0.13 & 5 & 0.65 \\
\hline 2 & $\begin{array}{l}\text { Tempat strategis, } \\
\text { luas, dan nyaman }\end{array}$ & 0.07 & 1 & 0.07 \\
\hline 3 & $\begin{array}{l}\text { Menyediakan } \\
\text { fasilitas wifi, } \\
\text { toilet, dan } \\
\text { musholla }\end{array}$ & 0.09 & 2 & 0.18 \\
\hline 4 & $\begin{array}{l}\text { Menyediakan } \\
\text { menu yang } \\
\text { bervariasi }\end{array}$ & 0.09 & 3 & 0.27 \\
\hline 5 & $\begin{array}{l}\text { Menyediakan } \\
\text { menu tambahan } \\
\text { (ayam geprek dan } \\
\text { milkshake) }\end{array}$ & 0.11 & 4 & 0.44 \\
\hline \multirow[t]{2}{*}{6} & $\begin{array}{l}\text { Loyalitas } \\
\text { konsumen tinggi }\end{array}$ & 0.11 & 3 & 0.33 \\
\hline & Weaknesses & & & \\
\hline 1 & $\begin{array}{l}\text { Sarana promosi } \\
\text { belum maksimal }\end{array}$ & 0.13 & 3 & 0.39 \\
\hline 2 & $\begin{array}{l}\text { Keberhasilan } \\
\text { media sosial } \\
\text { terbatas (jumlah } \\
\text { follower belum } \\
\text { menjangkau } \\
\text { secara luas) }\end{array}$ & 0.07 & 1 & 0.07 \\
\hline 3 & $\begin{array}{l}\text { Brand awareness } \\
\text { masih rendah }\end{array}$ & 0.11 & 4 & 0.44 \\
\hline 4 & $\begin{array}{l}\text { Kompetitor yang } \\
\text { lebih kuat }\end{array}$ & 0.09 & 3 & 0.27 \\
\hline & Total & 1 & & 3.11 \\
\hline
\end{tabular}

Sumber : Data Diolah (2021)

Tabel 2. menunjukan bahwa analisa faktor internal tertuang dalam faktor Strengths dan Weaknesses, di imana kekuatan terbaik Kafe dan Angkringan "Nu Laharjo" adalah harga produk terjangkau karena memiliki nilai skor tertinggi, sebesar 0.65, sedangkan kelemahan terbaik Kafe dan Angkringan " $\mathrm{Nu}$ Laharjo" adalah keberhasilan media sosial terbatas karena jumlah follower yang belum menjangkau secara luas yang dibuktikan dengan memiliki nilai skor terendah yaitu sebesar 0.07. Total skor menunjukkan nilai 3.11 artinya pihak kafe mampu mengatasi kelemahan yang ada dan menunjukkan posisi internal perusahaan yang kuat.

Tabel 3. Matrik EFE

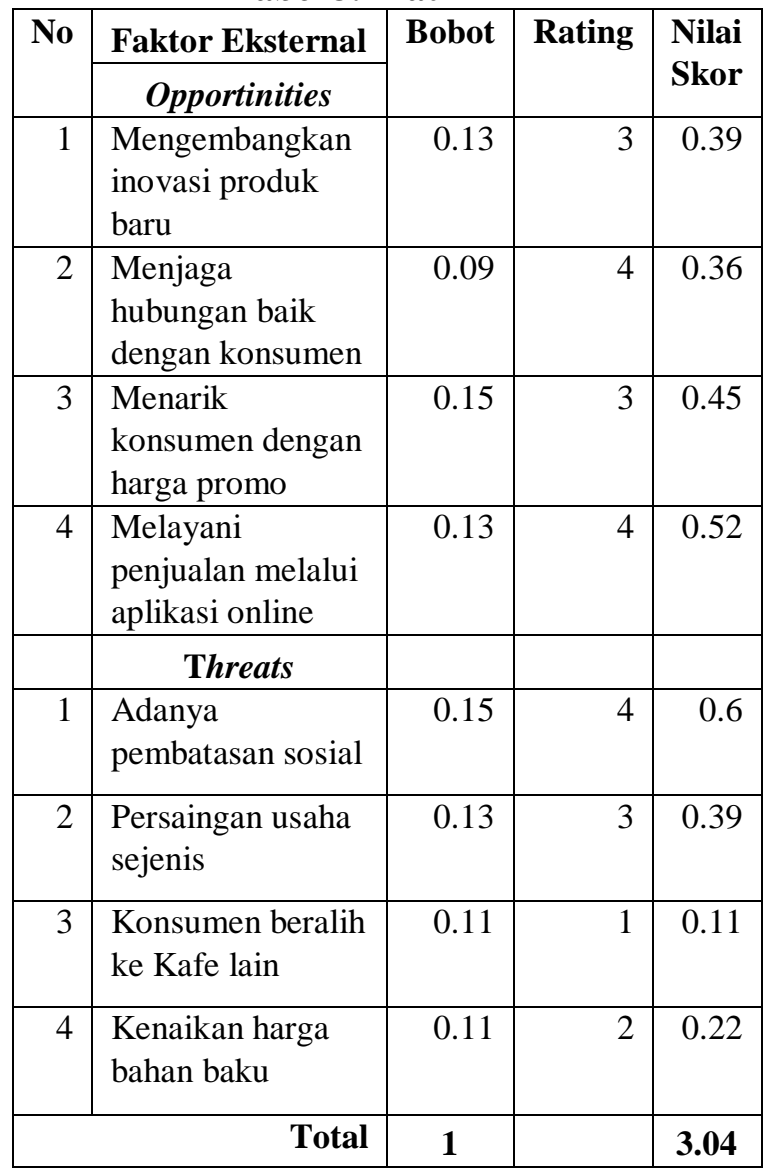

Sumber : Data Diolah (2021)

Tabel 3 terlihat analisis faktor eksternal yang meliputi opportunities dan threats, dimana peluang terbaik pada Kafe dan Angkringan $\mathrm{Nu}$ Laharjo terdapat pada melayani penjualan, melalui aplikasi online karena memiliki nilai skor tertinggi sebesar 0.52. sedangkan ancaman terbaik terdapat pada konsumen beralih pada kafe lain karena memiliki nilai skor terendah yaitu sebesar 0.11. Total nilai terlihat sebesar 3.04, artinya pihak kafe mampu menghadapi situasi yang mengancam dan mampu memanfaatkan peluang yang ada. Menurut Tambunan \& Agushinta (2020) matrik IFE dan EFE digunakan agar Kafe dan Angkringan "Nu Laharjo" memiliki gambaran secara jelas bagaimana menghadapi peluang dan ancaman 
berdasarkan kekuatan dan kelemahan yang dimiliki.

\section{Matrik "Grand Strategy"}

Matrik "Grand Strategy" berperan penting dalam mengkoordinasikan dan mengarahkan sumberdaya dalam mencapai tujuan dan sasaran perusahaan (Wahyuni dkk., 2020). Matrik "Grand Strategy" disusun berdasarkan dua dimensi yaitu posisi persaingan dan pertumbuhan pasar (Sanjaya dkk, 2020). Terlihat pada matrik "Grand Strategy" Kafe dan Angkringan "Nu Laharjo"pada Gambar 1.

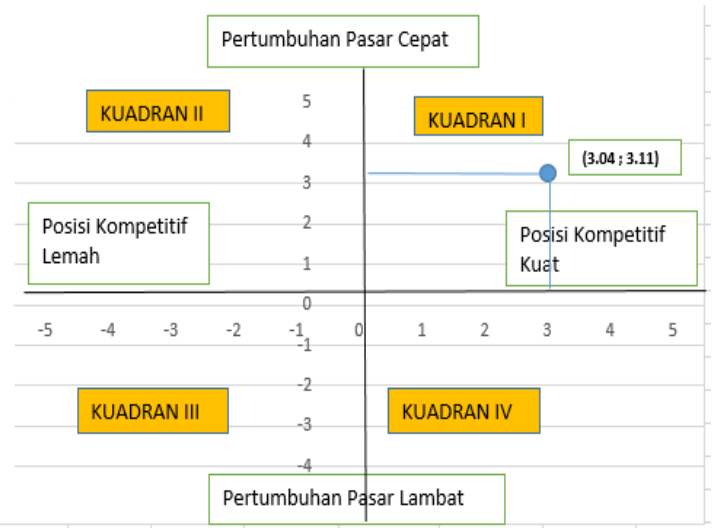

Gambar 2. Matrik Grand Strategy

Gambar 2., menunjukkan matrik "Grand strategy" menunjukkan bahwa posisi Kafe dan Angkringan "Nu Laharjo" berada pada Kuadran I, dimana perusahaan masih dalam posisi yang strategis dan baik. Menurut (Wahyuni dkk, 2020) bahwa terdapat beberapa strategi yang dapat digunakan pada perusahaan yang masuk di Kuadran I antara lain, pengembangan pasar, penetrasi pasar, pengembangan produk, integrasi ke depan, integrasi kebelakang, integrasi horisontal, dan diversifikasi konsentris.

\section{Formulasi Strategi Matrik SWOT}

Hasil matriks "Grand Strategy", maka diperlukan formulasi strategi yang dapat dilakukan oleh Kafe dan Angkringan " $\mathrm{Nu}$ Laharjo untuk menghadapi persaingan usaha. Formulasi" strategi dengan matrik SWOT digunakan untuk menghasilkan beberapa alternatif strategi, seperti strategi: $S O, W O, S T$, dan $W T$ yang dapat digunakan untuk mengembangkan bisnis di masa sekarang maupun masa yang akan datang (Sari dkk,

2021). Adapun formulasi strategi matrik SWOT dapat dilihat pada Tabel 4.

\section{PEMBAHASAN}

Berdasarkan hasil penelitian pada Kafe dan Angkringan "Nu Laharjo", maka didapatkan beberapa temuan, seperti: analisis SWOT, matrik IFE dan EFE, serta matrik "Grand Strategy". Pada Tabel 4. analisis SWOT teridentifikasi empat faktor, yaitu: strengths, weaknesses, opportunities, dan threats. strengths yang dimiliki oleh perusahaan. Terlihat bahwa Kafe dan Angkringan "Nu Laharjo" memiliki harga produk terjangkau, produk yang dijual bervariasi, seperti: "nasi goreng, mie goreng, aneka macam makanan ringan", serta menu tambahan yang sekarang menjadi keunggulan, yaitu: "ayam geprek dan milkshake." Lokasi kafe terletak pada tempat yang strategis, nyaman dan luas, serta menyediakan fasilitas wifi, toilet dan mushola.

Selain itu, kondisi interior juga didesain menarik, sehingga loyalitas konsumen tinggi karena suasana nyaman di kafe dapat membuat konsumen kembali datang ke kafe tersebut. Weaknesses di Kafe dan Angkringan "Nu Laharjo" menunjukkan bahwa sarana promosi masih belum maksimal, karena selama ini promosi hanya dilakukan melalui media sosial, seperti: Instagram, Facebook, Dan Whatsapp Story. Namun, follower yang dimiliki juga masih rendah artinya belum menjangkau secara luas masyarakat Kabupaten dan Kota Mojokerto. Selain itu brand awareness juga masih rendah serta kompetitor yang lebih kuat, karena posisi Kafe dan Angkringan dekat dengan kompetitor sejenis, seperti: "Budaya Coffee", "Pasta Kangen", "NCO".

Threats di Kafe dan Angkringan "Nu Laharjo" menunjukkan bahwa ancaman yang perlu diperhatikan adalah adanya pembatasan sosial, karena masa pasca pandemi ini membuat konsumen lebih berhati -hati untuk keluar rumah, jika kondisi Kafe sudah ramai maka konsumen yang ingin nongkrong akan mengurungkan niatnya, bahkan beralih pada Kafe lain. Terlebih lagi disekitar Kafe dan Angkringan "Nu Laharjo" banyak Kafe sejenis yang dibuka. Selain itu, kenaikan harga bahan baku juga menjadi ancaman, karena ketika harga bahan baku naik, maka harga produk juga naik, sehingga mempengaruhi keputusan konsumen dalam membeli produk.

Berdasarkan hasil analisis SWOT, maka dilakukan perhitungan dalam mengakumulasi 4 faktor yang digunakan dalam perumusan strategi. Keempat faktor tersebut dipilih yang 
memiliki nilai terbaik dari semua elemen yang terdapat pada matrik IFE dan EFE (Qanita, 2020).
Harga produk terjangkau menjadi faktor yang dapat menarik konsumen.

Tabel 4. Formulasi Strategi Matrik SWOT

\begin{tabular}{|c|c|c|}
\hline & $\begin{array}{l}\text { Strength (S) } \\
\text { 1. Harga produk terjangkau } \\
\text { 2. Tempat strategis, luas, dan } \\
\text { nyaman } \\
\text { 3. Menyediakan fasilitas Wifi, } \\
\text { toilet, dan Musholla } \\
\text { 4. Menyediakan menu bervariasi } \\
\text { 5. Menyediakan menu tambahan } \\
\text { (ayam geprek, nasi bertelor, dan } \\
\text { milkshake) } \\
\text { 6. Loyalitas konsumen tinggi }\end{array}$ & $\begin{array}{l}\text { Weakness (W) } \\
\text { 1. Sarana promosi belum } \\
\text { maksimal } \\
\text { 2. Keberhasilan media sosial } \\
\text { terbatas (jumlah follower belum } \\
\text { menjangkau secara luas } \\
\text { 3. Brand awareness masih rendah } \\
\text { 4. Kompetitor yang lebih kuat }\end{array}$ \\
\hline $\begin{array}{l}\text { Opportunity (O) } \\
\text { 1. Mengembangkan inovasi } \\
\text { produk baru } \\
\text { 2. Menjaga hubungan baik dengan } \\
\text { konsumen } \\
\text { 3. Menarik konsumen dengan } \\
\text { harga promo } \\
\text { 4. Melayani penjualan melalui } \\
\text { aplikasi online }\end{array}$ & $\begin{array}{l}\text { Strategi S-O } \\
\text { 1. Memberikan harga terjangkau } \\
\text { tanpa mengurangi citarasa } \\
\text { (S1, S6, O2, O3) } \\
\text { 2. Melakukan perbaikan fasilitas } \\
\text { seperti AC, Colokan listrik dan } \\
\text { sebagainya agar konsumen } \\
\text { merasa nyaman } \\
\text { (S3, S6, O2) } \\
\text { 3. Menciptakan produk baru yang } \\
\text { unik } \\
\text { (S4, S5, S6, O1, O2) } \\
\text { 4. Memperluas jaringan } \\
\text { pemasaran melalui komunitas, } \\
\text { pertemanan, dan aplikasi online } \\
\text { (S6, O2, O4) }\end{array}$ & $\begin{array}{l}\text { Strategi W-O } \\
\text { 1. Melakukan inovasi produk } \\
\text { yang menarik dan berbeda } \\
\text { dengan pesaing } \\
\text { (W3, W4, O1, O2) } \\
\text { 2. Mengadakan giveaway dan } \\
\text { memberikan promo menarik } \\
\text { pada event tertentu } \\
\text { (W1, O2, O3) } \\
\text { 3. Memanfaatkan seluruh media } \\
\text { sosial dalam memperkenalkan } \\
\text { usaha } \\
\text { (W1, W2, W3, O2) } \\
\text { 4. Memanfaatkan aplikasi online } \\
\text { dalam penjualan } \\
\text { (W2, W3, O2, O4) }\end{array}$ \\
\hline $\begin{array}{l}\text { Threat }(\mathbf{T}) \\
\text { 1. Adanya pembatasan sosial } \\
\text { 2. Persaingan usaha sejenis } \\
\text { 3. Konsumen beralih ke kafe lain } \\
\text { 4. Kenaikan harga bahan baku }\end{array}$ & $\begin{array}{l}\text { Strategi S-T } \\
\text { 1. Melakukan kerjasama dengan } \\
\text { penyedia layanan aplikasi } \\
\text { online } \\
\text { ( S6, T1, T2, T3) } \\
\text { 2. Menyediakan produk dengan } \\
\text { harga yang kompetitif } \\
\text { (S1, S6, T2, T4) } \\
\text { 3. Menyediakan tempat yang } \\
\text { nyaman dengan fasilitas } \\
\text { protokol kesehatan } \\
\text { (S2, S3, T2, T3) } \\
\text { 4. Mengadakan promosi tentang } \\
\text { menu baru yang ditawarkan } \\
\text { (S2, S3, T2, T3) }\end{array}$ & $\begin{array}{l}\text { Strategi W-T } \\
\text { 1. Membuat konten menarik } \\
\text { dalam meningkatkan promosi } \\
(\mathrm{W} 1, \mathrm{~W} 2, \mathrm{~W} 4, \mathrm{~T} 2, \mathrm{~T} 3) \\
\text { 2. Meningkatkan jangkauan } \\
\text { pemasaran } \\
\text { (W2, W3, T1, T2) } \\
\text { 3. Melakukan evaluasi mengenai } \\
\text { target yang ingin dicapai pihak } \\
\text { kafe } \\
\text { (W1, W2, W3, W4, T1,T2, T3) }\end{array}$ \\
\hline
\end{tabular}

Sumber: Data Diolah (2021)

Weaknesses yang memiliki nilai terbaik adalah keberhasilan media sosial yang terbatas artinya follower yang dimiliki masih sedikit, sehingga pihak kafe perlu mencari solusi dalam mengatasi masalah tersebut misalnya dengan mengunggah foto unik dan berjadwal, memasang tulisan akun media sosial pada setiap sudut kafe, sehingga dapat mendorong konsumen yang datang untuk menambahkankan akun media soial kafe dan Angkringan "Nu Laharjo". Setiawan dkk (2018) mengemukkan bahwa sebuah produk dapat divisualisasi dengan menarik disertai dengan ilustrasi bahan, rasa, dan harga, karena semakin menarik 
informasi yang ditampilkan semakin memberikan kesempatan konsumen untuk melakukan kegiatan lebih lanjut.

Matrik EFE juga menunjukkan bahwa nilai terbaik pada opportunities adalah melayani penjualan, melalui aplikasi online. Faktor penyebab dikarenakan dampak adanya wabah pandemi Covid-19. Pemerintah melarang masyarakat untuk keluar rumah, sehingga penjualan melalui aplikasi online menjadi pilihan masyarakat untuk membeli produk. Menurut Suryadi \& Ilyas (2018) bahwa perlunya pelaku bisnis dalam mengembangkan layanan untuk memenuhi keinginan masyarakat, sehingga layanan aplikasi online menjadi salah satu solusi, misalnya menggunakan aplikasi "Grab" atau "GoJek". Faktor threats yang memiliki nilai terbaik adalah konsumen beralih ke kafe lain, di mana faktor tersebut menjadi perlu diperhatikan oleh Kafe dan Angkringan "Nu Laharjo", karena mempertahankan konsumen lebih sulit dari pada mencari konsumen baru.

Menurut Erawati (2020) bahwa faktor faktor yang dapat mempertahankan loyalitas konsumen adalah mempertahankan kualitas produk, kualitas layanan, menjaga emosional. Artinya bahwa pihak kafe perlu memiliki keyakinan bahwa usahanya akan maju, sehingga akan mendatangkan ide untuk meningkatkan usahanya, serta harga produk karena konsumen akan lebih memilih produk bagus dengan harga terjangkau ataupun bersaing. Matrik "Grand Strategy" menunjukkan bahwa Kafe dan Angkringan "Nu Laharjo" berada pada Kuadran I, yaitu pada posisi persaingan yang kuat dan pertumbuhan pasar yang cepat. Sesuai dengan hasil yang didapatkan dari matrik "Grand Strategy", maka strategi yang dapat digunakan oleh pihak Kafe dan Angkringan "Nu Laharjo" tertuang dalam matrik SWOT yang dijabarkan menjadi strategi $S O, W O, S T$, dan WT.

Strategi SO (Strength dan
Opportinities) menjelaskan tentang cara
memanfaatkan kekuatan dalam merebut
peluang, yaitu: memberikan harga terjangkau
tanpa menghilangkan citarasa, melakukan
perbaikan fasilitas, seperti: AC dan colokan
listrik yang rusak untuk membuat konsumen
merasa nyaman, menciptakan produk baru unik
dan berbeda dari produk pesaing, serta
memperluas jaringan pemasaran melalui
komunitas, pertemanan dan aplikasi online.

Faktor penyebab dikarenakan semakin banyaknya layanan aplikasi online yang perlu dimanfaatkan untuk memudahkan konsumen yang tidak ingin keluar rumah dalam melakukan pembelian.

Strategi WO (Weakness dan Opportunities) menjelaskan bagaimana meminimalkan kelemahan dalam menghadapi peluang, yaitu: pihak kafe dapat melakukan inovasi produk yang menarik dan berbeda dengan pesaing; mengadakan give away dan promo menarik pada event tertentu; memanfaatkan seluruh media sosial dalam mengenalkan produk, seperti: Facebook, Instagram, Whatsapp Story, Path, Twetter, Dan Youtube; serta memanfaatkan aplikasi online dalam penjualan. Strategi $S T$ (Strength dan Threat) menunjukkan bagaimana menggunakan kekuatan dalam menghadapi ancaman, yaitu dengan cara melakukan kerjasama dengan penyedia layanan aplikasi online, seperti: GoJek, Uber, Shopee, dan penyedia layanan online lokal. Selain itu, menyediakan produk dengan harga yang kompetitif, menyediakan tempat yang nyaman dengan fasilitas protokol kesehatan mengingat masa pandemi Covid-19 belum berakhir, serta mengadakan promosi tentang menu yang ditawarkan.

Strategi WT (Weakness dan Treath) menjelaskan bagaimana meminimalkan kelemahan dengan menghindari ancaman, yaitu dilakukan dengan membuat konten menarik dalam meningkatkan promosi; jangkauan pemasaran, baik dilakukan dengan aktif di media sosial. Tujuan promosi adalah agar follower semakin meningkat; maupun dengan cara langsung dengan word of mouth. Selain itu, melakukan evaluasi pada target yang ingin dicapai pihak kafe, di mana evaluasi ini sangat penting untuk mengetahui kondisi kafe, sehingga perlunya evaluasi secara rutin dalam mencapai target yang diinginkan.

\section{KESIMPULAN}

Simpulan pada penelitian ini adalah teridentifikasi analisis SWOT, seperti: faktor kekuatan (strength), kelemahan (weaknesses), peluang (opportunities), dan ancaman (threats) pada Kafe dan Angkringan Nu Laharjo. Selain itu didapatkan formulasi strategi bersaing pada matriks IFE dan EFE, serta matrik Grand strategy. Matrik IFE menunjukkan bahwa pihak Kafe mampu mengatasi kelemahan yang ada serta memiliki posisi internal perusahaan yang 
kuat. Matrik EFE juga menunjukkan bahwa pihak Kafe mampu memanfaatkan peluang yang ada dan mampu menghadapi situasi yang mengancam. Matrik "Grand Strategy" memperlihatkan bahwa posisi Kafe dan Angkringan "Nu Laharjo" berada pada Kuadran I, di mana perusahaan masih dalam posisi baik.

Formulasi strategi dilakukan dengan menggunakan matrik SWOT yang dijabarkan pada strategi SO (Strength dan Opportinities), strategi WO (Weakness dan Opportunities), strategi ST (Strength dan Threat) dan strategi WT (Weakness dan Treath). Strategi tersebut perlu diimplementasikan oleh Kafe dan Angkringan "Nu Laharjo" agar dapat bertahan dalam persaingan.

\section{DAFTAR PUSTAKA}

Arifin, M. Z., Desembrianita, E., \& Surianto, M. A. (2021). Strategi pemasaran Aka Coffee Gresik di era pandemi covid-19 melalui analisis SWOT. Jurnal SENOPATI, April 2021, 2(2), 92-101.

Astuti, A. M. I., \& Ratnawati, S. (2020). Analisis SWOT Dalam Menentukan Strategi Pemasaran (Studi Kasus di Kantor Pos Kota Magelang 56100). Jurnal Ilmu Manajemen, 17(1), 58-70.

Dadang. (2020). Analisis Perancangan Strategi Dengan Menggunakan Matrik SWOT Pada MTs Negeri 7 Majalengka. Jurnal MADINASIKA Manajemen Dan Keguruan, Oktober 2020, 2(1), 1-9.

Emet, G., \& Merba, T. (2017). SWOT Analysis: a Theoretical Review. The Journal of International Social Research, $4,9-15$.

Erawati, S. H. (2020). Faktor - Faktor Yang Mempengaruhi Loyalitas Konsumen Terhadap Penggunaan E-Commerce. INSPIRASI (Jurnal Ilmu Sosial), 17(2), 304-315.

Evelyn. (2018). Analisis Manajemen Strategi Bersaing dengan Matriks IE, Matriks SWOT, dan Matriks QSPM Pada PT. XYZ. Jurnal Manajemen Bisnis Dan Kewirausahaan, 2(4), 99-105.

Kamaluddin, I. (2020). Analisis Swot Untuk Merumuskan Strategi Bersaing. Jurnal Ilmu Manajemen Terapan, 1(4), 342354. https://doi.org/10.31933/JIMT

Pratama, R., \& Rivai, H. A. (2021). Pengaruh Gaya Kepemimpinan Transformasional dan Budaya Kerja, Motivasi Kerja
Terhadap Kinerja Karyawan Pada Cafe dan Restoran di Kota Padang. Jurnal Riset Bisnis, April 2021, 4(2), 141-154.

Purwohandoyo, J., Lubis, B. T., \& Saputra, O. F. (2020). Aplikasi Analisis Swot Kuantitatif Untuk Formulasi Strategi Pengembangan Pariwisata Perdesaan Di Kawasan Lereng Merapi, Daerah Istimewa Yogyakarta. Jurnal Nasional Pariwisata, $\quad 9(1), \quad 66$. https://doi.org/10.22146/jnp.59458

Qanita, A. (2020). Analisis Strategi Dengan Metode Swot Dan Qspm (Quantitative Strategic Planning Matrix): Studi Kasus Pada D'Gruz Caffe Di Kecamatan Bluto Sumenep. Jurnal Ilmiah Manajemen, Vol. 1 No. 2, Oktober 2020, 53(9), 16891699.

Rawung, S. S., \& Salindeho, M. F. S. (2020). Small-Scale Industries Development Strategy in Bitung City Using SWOT Analysis and TOWS Strategy. Society, $8(2)$, 783-793. https://doi.org/10.33019/society.v8i2.269

Sanjaya, V., Shelawati, D., Ghati, L., \& Berama. (2020). Ife Efe Dan Grand Strategy Indsutri Kuliner. Jurnal Manajemen Bisnis Islam, 1(2), 159-170.

Sari, R. P., Mariam, I., \& Sinaga, M. O. (2021). Analisis Strategi Pengembangan Bisnis Melalui Matriks SWOT pada Startup Makanan Halal.id. Journal of Management and Business Review, 18(3), 630-639.

Setiawan, T. F., Suharjo, B., \& Syamsun, M. (2018). Strategi Pemasaran Online UMKM Makanan (Studi Kasus di Kecamatan Cibinong). MANAJEMEN IKM: Jurnal Manajemen Pengembangan Industri Kecil Menengah, September 2018, 13(2), 116. https://doi.org/10.29244/mikm.13.2.116126

Sitorus, B. P., Nursyamsi, I., \& Sumardi. (2019). Strategi Keunggulan Bersaing Pt . Semen Tonasa Dengan Swot Dan Qspm Competitive Advantage Strategy of Pt . Semen Tonasa. Hasanuddin Journal of Bussiness Strategy, 1(1).

Suryadi, D. F., \& Ilyas, M. I. F. (2018). Adopsi Online Food Delivery Service Bagi Wirausaha Pemula. Ilmu Administrasi, Akuntansi, Bisnis, Dan Humaniora, 2018, 75-80. 
Syamruddin, S. (2020). Analisis Kelayakan Usaha Baby Buncis Kenya Kelompok Tani "Baby French Farmer Group" Dari Aspek IFAS, EFAS, dan IE. Jurnal Madani: Ilmu Pengetahuan, Teknologi, Dan Humaniora, Maret 2020, 3(1), 118131.

https://doi.org/10.33753/madani.v3i1.100

Tambunan, R. J., \& Agushinta, D. (2020). Analisis Strategi Bisnis Pt. Tolu Dengan Pendekatan Bmc Menggunakan Metode Efas, Ifas Dan Swot. Sistemasi, September 2020, 9(3), 435. https://doi.org/10.32520/stmsi.v9i3.774

Tuncay, \& Musa. (2015). Munich Personal RePEc Archive SWOT Analysis in Strategic Management and a Sample Application in Public. 67213.

Wahyuni, N., Kamsin, D., Febianti, E., \& Bimantara, G. I. (2020). Quantitative Strategic Planning Matrix Pemasaran Air Minum dalam Kemasan. Performa: Media Ilmiah Teknik Industri, 19(1), 39-48. https://doi.org/10.20961/performa.19.1.409 96. 